\title{
A Motor Management Strategy for Optimising Energy Use and Reducing Life Cycle Costs
}

\author{
V. Dlamini, R. C. Bansal, R. Naidoo \\ Department of Electrical Electronic \& Computer Engineering, University of Pretoria, Pretoria, South Africa \\ Email: muzid@tuks.co.za
}

Received January 2014

\begin{abstract}
With increasing energy costs and renewed focus on using energy in ways that support the environment, a structured approach is required to ensure that energy is used efficiently. A comprehensive motor management strategy to reduce motor life cycle costs while increasing reliability is presented. The application of energy management principles is combined with benefits that can be obtained from using energy-efficiency motors. An economic model for determining the optimal time a motor should be replaced with a higher efficiency motor is proposed. The strategy presented incorporates benefits that can be obtained from using in-situ motor efficiency estimation and condition monitoring techniques as part of a motor management system.
\end{abstract}

\section{Keywords}

Motor Efficiency; Motor Management; Maintenance; Vibration Signature Analysis; Energy Efficiency; Motor Replacement

\section{Introduction}

Electric motors are a key part of industry. They are used in a wide variety of equipment and processes. This includes fans, pumps, compressors, conveyor drives and machine tools. Motors are a leading power consumer due to their widespread use in industry. Motors can account for more than two thirds of the electrical power consumption in some countries. As the cost of electricity continues to increase, motors provide a great opportunity to reduce energy consumption.

Energy conservation technologies can reduce the energy consumption by an estimated 11\% to 18\% [1]. The reduced energy consumption results in a reduction in operating costs for businesses. This means less power has to be generated which, in turn reduces the harmful greenhouse gases emitted into the atmosphere.

Motor management can be described as strategies that focus on reducing the total cost of ownership of motors in a plant. The cost of ownership of motors includes the energy cost of running a motor, the cost of purchasing motors, the cost of maintaining motors, and the business cost incurred as a result of motor-related process interruptions [2]. A comprehensive motor management strategy incorporates the benefits of the latest technology and 
the application of best practices to the repair of motors in a plant. The ultimate aim of a motor-management strategy is to ensure a reliable plant at the lowest possible motor-related costs [3].

In this paper an overview of energy management is presented with a focus on electric motors. The benefits that can be obtained from using energy efficient motors are discussed. The cost savings that can be obtained through developing a structured approach to motor management are investigated. An economic model for determining the optimal time a motor should be replaced with a high efficiency motor is presented. The application of non-intrusive motor efficiency estimation and condition monitoring techniques is proposed as part of an integrated real time motor management system.

\section{Energy Management Overview}

An energy management program must seek to minimize the adverse impact on the environment. This can be achieved by understanding how the business uses energy and creating an awareness of energy saving. Efficient maintenance structures must be put in place [4].

Motor energy management strategies focus on load management, efficiency management and power factor correction [5]. A starting point for energy management is to perform an energy audit. This determines how power is consumed by the plant. Once an audit has been conducted, energy-saving opportunities can be identified. Plans for implementing them can be put in place. The energy audit identifies the following areas for potential improvements [4].

- The efficiency of the operations.

- The efficiency of the billing systems.

- Efficiency of the maintenance activity.

The efficiency of operations entails assessing the design and operation of the different processes in the plant to determine if they use energy efficiently. A motor energy audit must focus on the motor sizes and determine how well they are matched to the load requirements. Incorrect motor sizing has a negative impact on the efficiency of the motor. A motor that is larger than required results in operation at a lower efficiency. This translates to energy loss. Motors usually operate at their highest efficiency at between $75 \%$ to $80 \%$ of their rated load. The efficiency and power factor both decline as the load reduces. Motors are often oversized to allow for higher future loads or to make provision for short-term load requirements [3].

The billing system must be analyzed to ensure that the economic tariff structure is optimal while considering the plant's operational requirements. It is also important to determine the contribution made by motors to the overall energy consumption of a plant. This allows for the calculation of potential savings which can be realized through motor management strategies. The maintenance activity within the plant has to be assessed to determine the standard. Poor maintenance results in a reduction in efficiency.

A portable instrument for measuring and logging of motor load profiles and estimating efficiency is a valuable tool to conduct an energy audit. It could further be used to determine the power factor of the motor.

Once the data from an audit has been collected, it must be analyzed and opportunities for energy savings should be identified. Action plans must then be put in place. The following alternatives can be implemented:

a) The motor can be kept intact.

b) The motor can be replaced with a new standard motor.

c) The motor can be replaced immediately with a higher efficiency motor.

Control systems such as flux optimization or variable speed drives can be implemented to improve the efficiency of the motor [5].

The action taken depends on the load or process requirements. After analyzing the plant processes, opportunities for optimizing the process efficiency through implementing a control strategy can be identified. A thorough economic comparison of the available options is necessary to maximize savings.

\section{Motor Replacement}

In this section the development of a motor replacement strategy is discussed. Tools for economic analysis of the potential benefits of replacing motors with energy efficient motors are presented.

\subsection{Motor Replacement Strategy}

The cost and environmental benefits of replacing a standard efficiency motor with an energy-efficient motor 
have been highlighted. A motor replacement strategy has to be developed to achieve the benefits. This ensures that clear guidelines exist on how to ensure that motors are operated with the desired reliability and at optimal life cycle costs. An installed motor can be replaced with an energy efficient motor under the following conditions [6]:

a) When a motor has failed;

b) When a new motor is required for an application; and

c) When a motor currently in operation is to be replaced.

In each of the cases an economic evaluation of the available options has to be performed to quantify the benefits. A repair/replacement strategy has to consider the following:

- The impact on energy usage;

- The cost of the capital to be spent;

- The motor size;

- The motor repair cost;

- The motor operating and repair history;

- The replacement motor cost; and

- The availability of a replacement [7].

The energy usage and efficiency of the installed motor must be compared to an energy-efficient replacement motor. An energy-efficient motor provides an opportunity to reduce the cost of energy for operating the plant. There is an opportunity to assess if the motor is properly sized for the load. An oversized motor operates at a lower efficiency level. This results in energy wastage. The repair cost can be used to make the repair/replace decision. If the motor repair cost exceeds a certain percentage of the replacement cost, the motor must be replaced with an energy-efficient motor. The motor operating and repair history is an important factor when making the decision. A strategy for repairing/replacing a motor must consider the reliability of the motor and the probability of future failures. If a motor has been repaired for a predetermined number of times, it should be scrapped. The availability of an energy-efficient replacement motor needs to be investigated. If there is a long lead time for the replacement motor, then the production losses incurred until replacement might be excessive. The lead time for the motor repair has adverse consequences if there are no spares and it runs critical process equipment. The above-mentioned factors need to be taken into account when doing an economic evaluation.

New installations present a good opportunity to introduce energy-efficient motors on a plant. The plant will yield benefits of using energy-efficient motors. The motor strategy for a plant must specify that all new motor installations use energy-efficient motors. A detailed analysis can be done to determine the feasibility of introducing an energy efficient motor as a replacement for a standard-efficiency motor that is still operational. A proposal for how motor replacement decision should be made is presented after a discussion on how motor maintenance influences such decisions.

\subsection{Economic Analysis}

In order to replace a standard efficiency motor with an energy-efficient motor, a capital investment is required. Before a capital investment is made, an economic analysis has to be performed to determine the return on investment. The return on investment is used to determine the economical feasibility of purchasing a new motor. A challenge in implementing a motor replacement or repair strategy is that the financial benefits of the investment may only be realised a few years later. The justification for the capital investment has to be made at the time the motor is replaced. Methods for performing the required economic analysis are presented in this section.

When comparing different economic investment options, it is necessary to convert them to a common base. Numerous techniques can be used to enable such a comparison. The most widely used methods for enabling economic comparison are the payback, net present value, internal rate of return, project balance and annual equivalent methods. Although all of the tools mentioned can be used, the preferred methods are the net present value and payback methods. These two methods and their application to motor comparison are investigated in detail [4].

To evaluate as to whether replacing a motor with an energy-efficient motor is feasible, information on the process and motors is required. The electricity tariff structure, annual motor load profiles and motor efficiency curves are required to determine the annual power consumption of the motors to be compared. In a plant where there is an established energy-management structure, motor load profiles for each motor may exist. Where such information is not readily available, a power-logging instrument can be used to determine the motor load profile. 
The efficiency estimation technique presented in [8] can be used to determine the motor efficiency curve at each point of the motor load cycle. The efficiency curve of the energy-efficiency replacement motor can be requested from the motor manufacturer. The effective interest, energy cost inflation rate, cost of motor replacement and its expected operating life are additional information required to determine the net present value of the investment.

The annual savings that will be realised by replacing a motor with an energy-efficient motor are given by (1), [9].

$$
A_{\text {saving }}=P_{\text {out }} L_{r} C\left(\frac{1}{E_{c}}-\frac{1}{E_{r}}\right)
$$

where $P_{\text {out }}$ is the motor rated power in $\mathrm{kW}, L$ is the percentage of full load divided by $100, h_{r}$ is the annual motor operating hours, $C$ is the average energy cost per $\mathrm{kWh}, E_{c}$ is the efficiency of the motor currently installed and $E_{r}$ is the efficiency of the energy-efficient replacement motor. In (1) it is assumed that the motor will operate at the same load when it is in service. In order to be able to compare the total savings that will be achieved, the net present value of the savings have to be calculated over the motor's expected operating life.

Once the annual savings have been determined, the net present value of the savings that will accrue over the motor's operating life can be determined. The net present value is a method that is used to bring the savings that will be realised over an extended period to their present equivalent. It takes the time value of money [4] into account. This calculation must include the cost of the capital required to purchase the new motor and a projection of the expected inflation rate for the cost of energy over the operating life of the motor. To determine the present value of the savings, it is necessary to calculate the effective interest rate using (2).

$$
i=\frac{100+r_{2}}{100+r_{1}}-1
$$

where $i$ is the effective interest rate, $r_{1}$ is the expected annual energy cost inflation rate and $r_{2}$ is the required internal rate of return on investments. The inflation rate and internal rate of return are assumed to be constant over the calculation period. After the effective interest rate has been calculated, the present value of the savings to be obtained can be determined from (3).

$$
N P V_{\text {saving }}=A_{\text {saving }} \frac{(1+i)^{n}-1}{i(1+i)^{n}}
$$

where $A_{\text {saving }}$ is the annual savings, $i$ is the effective interest rate and $n$ is the expected operating life of the new motor. The present value of the savings obtained can then be compared to the expense that will be incurred in purchasing the new motor. If the cost of the new motor is less than the net present value of the savings that will be achieved, a business case can be presented.

In providing economic justification for motor replacement, the payback period can be used as an alternative method for making the decision. The payback period for a motor replacement study is the time it will take for the benefits of replacing the current motor to exceed the capital invested in purchasing the new motor. The payback period can be calculated using (4), [9].

$$
n_{P B}=\frac{\ln \left(-\frac{A_{\text {saving }}}{i C_{\text {motor }}-A_{\text {saving }}}\right)}{\ln (1+i)}
$$

where $n_{P B}$ is the payback period in years, $A_{\text {saving }}$ is the annual savings, $i$ is the effective interest rate and $C_{\text {motor }}$ is the cost of the replacement motor. The cost of the new motor must include labour and downtime for the installation and uninstalling. When using the payback period for deciding the feasibility of replacing a motor, a project with a shorter payback period is most feasible.

In determining the annual savings it should be noted that Equation (1) is only applicable to motors that operate under constant load. This is because the efficiency of both motors under consideration will vary with different loading points. The annual savings do not take into account the demand charge for electricity. In cases where the motor is considered to make an appreciable contribution to the maximum demand, the annual energy savings 
calculation has to be modified to take this into account [10]. The power saved in $\mathrm{kW}$ can be calculated using (5).

$$
P_{\text {saving }}=P_{\text {out }} L\left(\frac{1}{E_{c}}-\frac{1}{E_{r}}\right)
$$

The annual savings that will be achieved by reducing the maximum demand are determined using (6).

$$
D_{\text {savings }}=12 \times P_{\text {saving }} \times D_{c}
$$

where $P_{\text {saving }}$ is the power saving in $\mathrm{kW}$ and $D_{c}$ is the demand charge. The total annual saving, $T_{\text {saving }}$ is given by (7). The total annual saving can be substituted for the annual savings in the expression for calculating the net present value and the payback period:

$$
T_{\text {saving }}=A_{\text {saving }}+D_{\text {savings }}
$$

If the motor load profile is not constant the equations presented need to be applied to each relatively constant portion of the motor load cycle that is relatively constant.

An example of such a load profile is shown in Figure 1.

The annual savings are determined as follows:

1. The calculation would be done for each of the three loading points, A, B and C. The annual operating hours would be determined by multiplying the daily hours at each loading point by the number of days the motor operates per year.

2. The output power for each of the loading points would be determined.

3. The annual saving would be calculated using the efficiency at each loading point.

4. The total annual saving would be determined using (8) as the sum of the savings for each loading point:

$$
A_{\text {saving }}=\sum_{A}^{C} P_{\text {out }} L h_{r} C\left(\frac{1}{E_{c}}-\frac{1}{E_{r}}\right)
$$

In developing a motor replacement policy the tools that have been presented can be applied. It is recommended that minimum economic requirements be determined and adopted for a company. This guides decision making on motor replacement based on either the net present value or the payback period. A decision should not only be based on motor replacement cost. It must factor in the expected future repair costs of the older motor installed in the plant. A comprehensive economic analysis must also explore the benefits obtained from power factor correction and the impact of available rebate programmes for energy-efficient motors. This will form an integral part of a motor-management strategy.

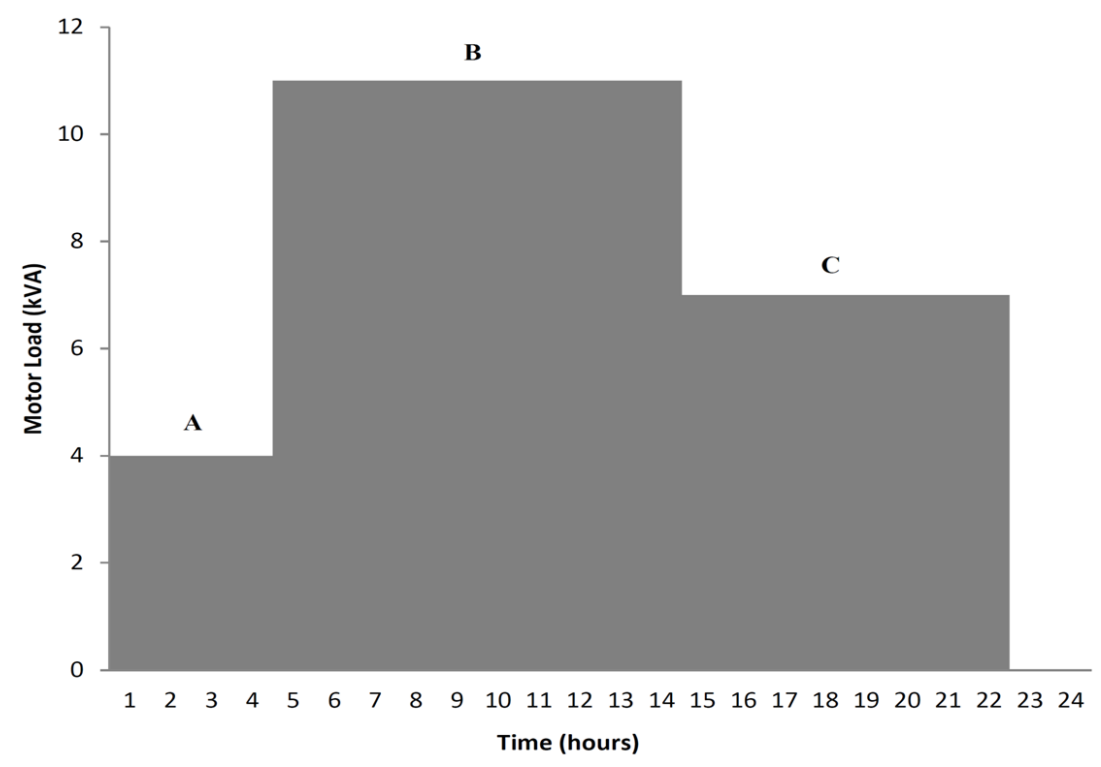

Figure 1. Motor load daily load profile. 


\section{Motor Maintenance}

The importance of a good maintenance strategy in an organization is often understated. Table $\mathbf{1}$ shows the contribution made by maintenance-related to the total operating costs [11]. This varies across different industry sectors. The maintenance cost is made up of the following components.

a) The direct cost of repairs

b) The cost of any pro-active work (labor, materials, contractor, etc)

c) The cost of lost revenue and reputation due to downtime

d) The cost of any penalties that are incurred as a result of damaged products or operating systems

It is can be seen from Table 1 that the cost of maintenance can be too significant to ignore in any plant. A good motor maintenance program extends the life of motors and improves system availability. This will result in a reduction in maintenance costs and downtime-related losses [3]. A motor-maintenance strategy must have guidelines for motor storage, installation, operation and repair.

Motors that are kept in storage for have a higher probability of failure if they are not stored according to best practices. The way in which a motor is installed has a significant impact on its reliability and operating life. When a motor is installed it is essential to ensure that is has the proper foundation and alignment procedures in place to minimize additional stresses to the motor. This can exceed the design limits [3]. Motors should be operated according to the manufacturers' guidelines to ensure that they achieve the design life.

A reliability-centred maintenance (RCM) approach has been found to be effective for motors [12]. RCM is a proactive maintenance strategy that has processes for anticipating which failure modes will occur [11]. Once the failure modes have been determined the consequences of each failure mode are analyzed. Plans are developed to eliminate or minimize the consequences of each of the failure modes.

The repair of motors presents an opportunity to implement policies that will result in long-term savings. The repair of motors must be governed by guidelines to ensure repairs are only carried out when it is financially feasible. Managing motor repairs starts with establishing repair specifications and identifying suitable suppliers that can provide high-quality repairs [7]. Agreements must be put in place with supplies to ensure that the repair of motors is done according to industry best practices. The motor repair decision flowchart in Figure 2 illustrates how decisions can be made when a motor fails in order to minimize the life cycle costs. Keeping a detailed motor repair history is important. Analyzing the trends can allow for estimating the life of the motor based on its reliability and age. This can prevent the repair of a motor that is near the end of its life and allows for the introduction of an energy-efficient motor in its place. The proposed decision-making process focuses on using all available data to make decisions that will realize cost savings over the operating life of the motor and plant. It guides a motor manager to take a holistic approach that takes into account energy efficiency and long-term benefits.

\section{Motor Management Strategy}

The discussions of the preceding sections lead to the development of the proposed motor-management strategy to ensure that motors in a plant have the lowest possible operating cost and very high reliability. A total motor-management approach with real time efficiency, load factor, power factor and vibration-based condition monitoring is proposed. The collected date will be stored on a database for use in the RCM based approach. With the availability of the relevant data, the RCM process should provide a comprehensive preventative maintenance program that will ensure that motors operate at high reliability.

Table 1. Contribution of maintenance to operating costs.

\begin{tabular}{cc}
\hline Industry & Contribution (\%) \\
\hline Mining & $20-50$ \\
Primary metals & $15-25$ \\
Electric utilities & $15-25$ \\
Manufacturing & $5-15$ \\
Processing & $3-15$ \\
Fabrication and assembly & $3-5$ \\
\hline
\end{tabular}




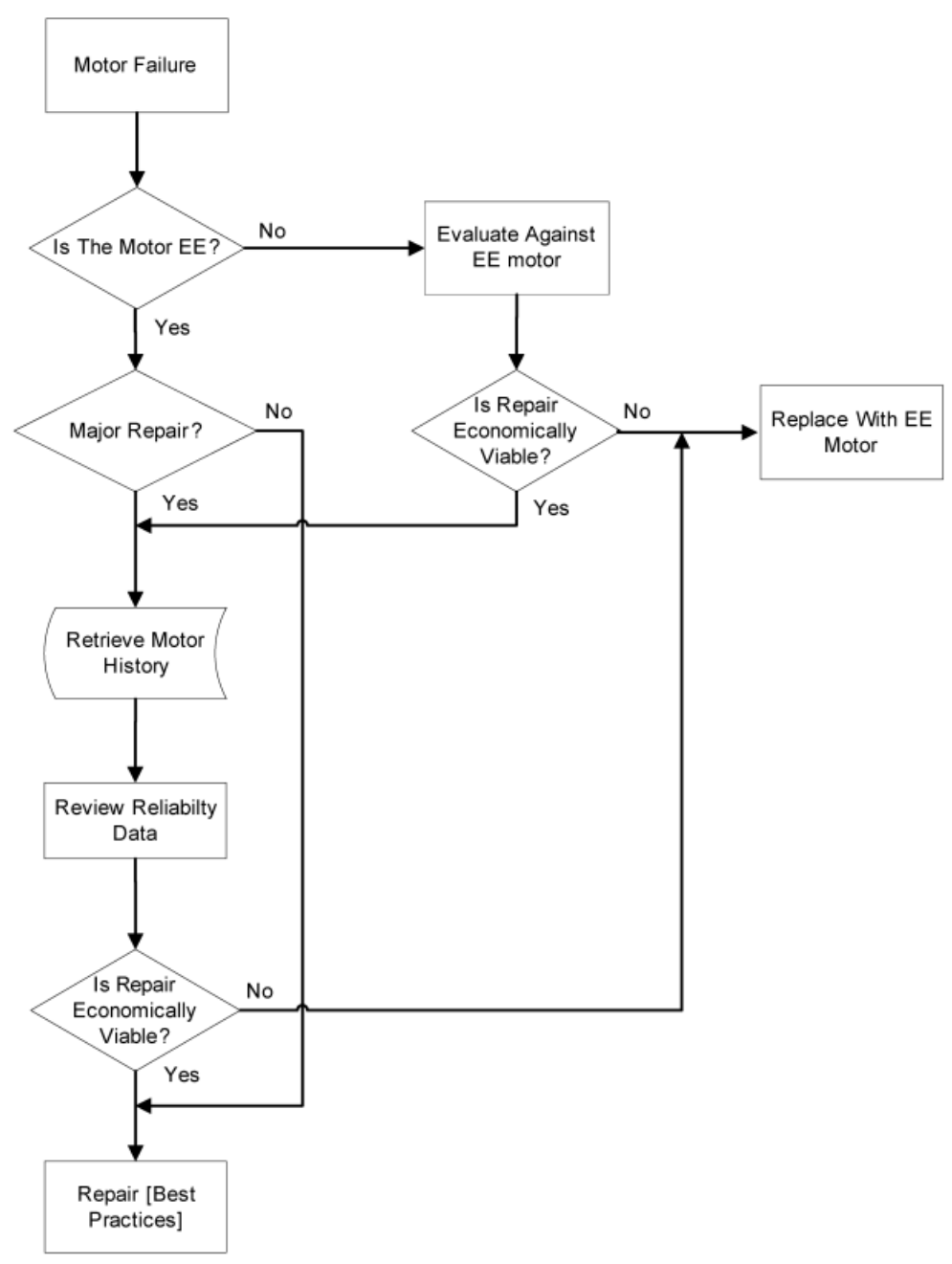

Figure 2. Motor repair decision flowchart.

An accurate method of estimating the efficiency of in-service motors is needed in order to determine the performance of installed motors without disrupting the motor driven process. In the proposed system the motor efficiency is estimated using a non-intrusive implementation of the compensated slip method. The motor speed is accurately estimated using motor vibration signature analysis [8]. The estimated efficiency can then be used to calculate the annual savings that will be realized by replacing an installed motor with an energy-efficient motor using (1). If the load in not constant than potential savings it can be obtained with (8). This can be incorporated into a motor management support system as described below.

The vibration signal may also used for condition monitoring since motor vibration signature analysis has been widely studied and applied in this field. Various types of motor faults can be detected from the vibration signature of a motor. These include faults such as winding faults, unbalanced stator and rotor parameters, broken rotor bars, eccentricity and bearing faults. The faults are detected as harmonics using vibration signature analysis [13]. The condition monitoring data should be used as input data in the RCM system. It provides the data required to successfully implement the replacement decision model in Figure 2.

A motor management support system that will make implementing the motor-management strategy easier and more efficient should be used. In Figure 3 the proposed plant wide motor management system is shown. This system consists of local field instruments at each motor for measuring its voltage, current and vibration. The collected data are sent via a wireless network to a central processor. At the central processor the non-intrusive speed and efficiency estimation technique is implemented [8].

Energy usage and reliability indicators for each motor can also be calculated at the central server. 


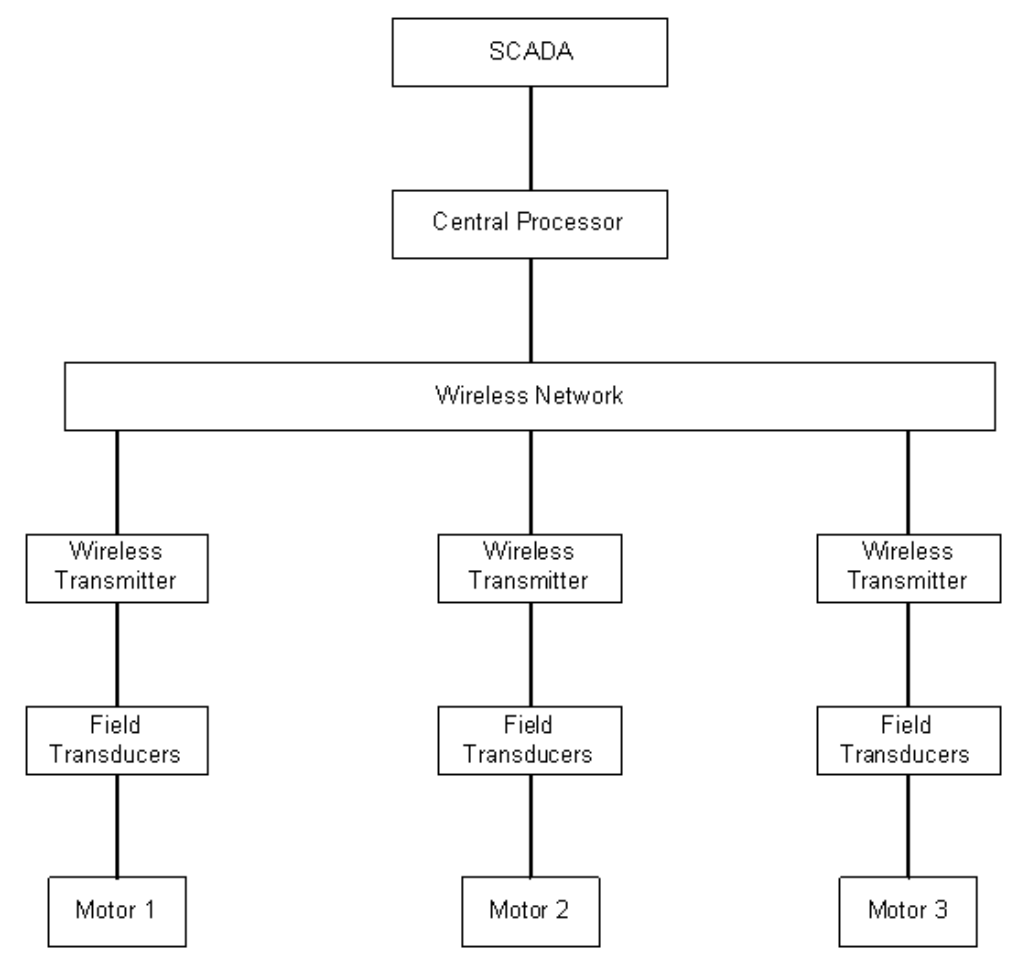

Figure 3. Motor management support system.

The proposed system should include the vibration based condition-monitoring tools with the fault detection algorithms implemented on the centralised processor. The processed data are sent to a Supervisory Control and Data Acquisition (SCADA) system so that historic data can be accessed for use in motor replacement and energy-management studies. Alarms can be sent to the SCADA system to inform control room operators or maintenance personnel of developing motor faults so that corrective action can be planned and scheduled. This will result in cost saving because unplanned downtime will be reduced.

\section{Conclusions}

An overview of motor energy management has been presented. Tools for performing an economic comparison of motors were discussed. The tools can be used to determine the annual savings that can be realized by using an energy-efficiency motor, as well as the payback period on the initial capital investment. The non-intrusive compensated slip method can be used to estimate the efficiency of an installed motor. This enables the above-mentioned calculations to be made.

The motor speed estimation technique based on vibration signature analysis can be used for detecting numerous fault conditions. A method for deciding how to handle motor failures has been proposed. This method takes into account the economic aspects of repairing the motor, whilst considering the reliability history of the motor. It provides a guideline for how energy efficient motors can be introduced taking into account the life cycle costs including the cost of energy.

A comprehensive motor-management strategy is proposed. This motor management strategy centres on finding the correct balance for energy efficiency, motor reliability and maintenance costs. This is achieved by using a motor-management system built around a network of field sensors to provide real-time data on the condition and performance of motors in a plant. This allows for proactive decisions to be made to minimize breakdowns and optimize energy usage.

\section{References}

[1] Saidur, R. (2010) A Review on Electrical Motors Energy Use and Energy Savings. Renewable and Sustainable Energy Reviews, 14, 877-898. http://dx.doi.org/10.1016/j.rser.2009.10.018 
[2] Mason, I. and Jones, T. (2004) Proactive Motor Management Can Help Reduce Operating Costs in the Pulp \& Paper Industry. Proceedings of the Pulp and Paper Industry Technical Conference, Boston, 27 June-1 July 2004, 70-72.

[3] Basso, D., Nyberg, C. and Yung, C. (2007) The Repair/Replace Decision from a Total Motor Management Perspective. Proceedings of the Pulp and Paper Industry Technical Conference, Williamsburg, 24-28 June 2007, $235-241$.

[4] Capehart, B.L., Turner, W.C. and Kennedy, W.J. (2012) Guide to Energy Management, Energy Management. 7th Edition, The Fairmont Press, Lilburn.

[5] Li, Y. and Yu, H. (2007) Energy Management for Induction Motors Based on Non-Intrusive Efficiency Estimation. Proceedings of the International Conference on Electrical Machines and Systems, Seoul, October 2007, 1763-1766.

[6] Akbab, M. (1999) Energy Conservation by Using Energy Efficient Electric Motors. Applied Energy, 64, 49-158.

[7] Whelan, C. Sassano, E. and Kelley, J. (2004) Management of Electric Motor Repair. Proceedings of the Petroleum and Chemical Industry Technical Conference, Wilmington, 13-15 September 2004, 279-288.

[8] Dlamini, V., Naidoo, R. and Manyage, M. (2013) A Non-Intrusive Method for Estimating Motor Efficiency Using Vibration Signature Analysis. International Journal of Electrical Power and Energy Systems, 45, 384-390. http://dx.doi.org/10.1016/j.ijepes.2012.09.015

[9] Phumiphak, T., Kedsoi, T. and Chat-Uthai, C. (2005) Energy Management Program for Use of Induction Motors Based on Efficiency Prediction. Proceedings of IEEE Region 10 Conference, Melbourne, 21-24 November 2005, 1-6.

[10] Eltom, A. and Aziz, M.A. (2005) The Economics of Energy Efficient Motors during Unbalanced Voltage Conditions. Proceedings of IEEE PES Conference and Exposition in Africa, Durban, 11-15 July 2005, 378-384.

[11] Campbell, J.D. and Reyes-Picknell, J.V. (2006) UPTIME Strategies for Excellence in Maintenance Management. 2nd Edition, Productivity Press, New York.

[12] Penrose, H.W. (2005) RCM-Based Motor Management. Proceedings of Electrical Insulation Conference and Electrical Manufacturing Expo, Chesapeake, 26 October 2005, 187-190.

[13] Singh, G.K. and Kazzaz, S.A.S.A. (2003) Induction Machine Drive Condition Monitoring and Diagnostic ResearchA Survey. Electric Power Systems Research, 64, 145-158. http://dx.doi.org/10.1016/S0378-7796(02)00172-4 